\title{
Evaluation of associations between estimates of particulate matter exposure and new onset type 2 diabetes in the REGARDS cohort
}

\author{
Tara P. McAlexander ${ }^{1 凶}$, S. Shanika A. De Silva ${ }^{1}$, Melissa A. Meeker ${ }^{1}$, D. Leann Long ${ }^{2}$ and Leslie A. McClure $^{1}$
}

(c) The Author(s) 2021

BACKGROUND: Studies of $\mathrm{PM}_{2.5}$ and type 2 diabetes employ differing methods for exposure assignment, which could explain inconsistencies in this growing literature. We hypothesized associations between $\mathrm{PM}_{2.5}$ and new onset type 2 diabetes would differ by $\mathrm{PM}_{2.5}$ exposure data source, duration, and community type.

METHODS: We identified participants of the US-based REasons for Geographic and Racial Differences in Stroke (REGARDS) cohort who were free of diabetes at baseline (2003-2007); were geocoded at their residence; and had follow-up diabetes information. We assigned $\mathrm{PM}_{2.5}$ exposure estimates to participants for periods of 1 year prior to baseline using three data sources, and 2 years prior to baseline for two of these data sources. We evaluated adjusted odds of new onset diabetes per $5 \mu \mathrm{g} / \mathrm{m}^{3}$ increases in $\mathrm{PM} \mathrm{M}_{2.5} \mathrm{using}$ generalized estimating equations with a binomial distribution and logit link, stratified by community type.

RESULTS: Among 11,208 participants, 1,409 (12.6\%) had diabetes at follow-up. We observed no associations between $\mathrm{PM}_{2.5}$ and diabetes in higher and lower density urban communities, but within suburban/small town and rural communities, increases of $5 \mu \mathrm{g} / \mathrm{m}^{3}$ $\mathrm{PM}_{2.5}$ for 2 years (Downscaler model) were associated with diabetes (OR [95\% Cl] = $1.65[1.09,2.51], 1.56$ [1.03, 2.36], respectively). Associations were consistent in direction and magnitude for all three $\mathrm{PM}_{2.5}$ sources evaluated.

SIGNIFICANCE: 1 - and 2-year durations of $\mathrm{PM}_{2.5}$ exposure estimates were associated with higher odds of incident diabetes in suburban/small town and rural communities, regardless of exposure data source. Associations within urban communities might be obfuscated by place-based confounding.

Keywords: Air pollution; Diabetes; Particulate matter; Exposure assignment; Community type Journal of Exposure Science \& Environmental Epidemiology (2022) 32:563-570; https://doi.org/10.1038/s41370-021-00391-9

\section{INTRODUCTION}

Particulate matter with a diameter $\leq 2.5$ microns $\left(\mathrm{PM}_{2.5}\right)$ is a ubiquitous ambient air pollutant with documented negative impacts on human health in epidemiologic studies [1, 2]. Mechanisms underlying documented associations between $\mathrm{PM}_{2.5}$ and health impacts include induction of oxidative stress, systemic inflammation, and endothelial dysfunction [2]. There is biologic rationale for associations between ambient $\mathrm{PM}_{2.5}$ exposures and the development of type 2 diabetes [2]. Specifically, systemic inflammation [3] and consequential metabolic dysfunction [4] are directly related to the development of type 2 diabetes [5-7]. Indirectly, exposure to $\mathrm{PM}_{2.5}$ can increase blood pressure and exacerbate hypertension [8], which is known to contribute to the development of type 2 diabetes [9].

While epidemiologic studies have extensively evaluated associations between $\mathrm{PM}_{2.5}$ and cardiovascular and respiratory disease and found consistent adverse associations, studies of the associations between $\mathrm{PM}_{2.5}$ and type 2 diabetes are less prevalent and demonstrate mixed results [10-16]. Although an increasing number of epidemiologic studies have found positive associations between
$\mathrm{PM}_{2.5}$ and traffic-related $\mathrm{PM}$ exposures and type 2 diabetes outcomes [10-12, 15, 17-19], other robust epidemiology studies have found null associations [13, 14, 20, 21]. Inconsistencies in findings could be due to differences in $\mathrm{PM}_{2.5}$ composition and estimation by community types and regions; by population differences; and by exposure assignment choices. These decisions are a challenge in the epidemiology of $\mathrm{PM}_{2.5}$ and type 2 diabetes and include: the exposure model used (i.e., monitor-dependent, emissions-based, satellite-derived); the exposure duration and latency period assigned prior to diabetes outcome assessment [22]; the consideration of confounders (temperature, proximity to roadways, and co-pollutants such as ozone and oxides of nitrogen $\left.\left[\mathrm{NO}_{\mathrm{x}}\right]\right)$; and the consideration of the chemical constituents of $\mathrm{PM}_{2.5}$.

Another challenge in understanding the epidemiology of $\mathrm{PM}_{2.5}$ and type 2 diabetes is the ability to adequately account for multiple risk factors for diabetes onset that occur at the community level (e.g., neighborhood walkability, healthy food access, availability of recreational spaces, traffic-related pollutants) $[23,24]$. Often, these risk factors cluster within distinct community typologies [25-27]. Numerous studies have demonstrated that

${ }^{1}$ Department of Epidemiology and Biostatistics, Drexel University Dornsife School of Public Health, Philadelphia, PA, USA. ${ }^{2}$ Department of Biostatistics, University of Alabama at Birmingham School of Public Health, Birmingham, AL, USA. ${ }^{凶}$ email: tpm58@Drexel.edu

Received: 16 February 2021 Revised: 27 September 2021 Accepted: 27 September 2021

Published online: 16 October 2021 
$\mathrm{PM}_{2.5}$ levels are generally higher in cities than in rural areas and correlate with proximity to roadways $[28,29]$, thus complicating the epidemiologic evaluation of $\mathrm{PM}_{2.5}$ and type 2 diabetes. Stratifying analyses of $\mathrm{PM}_{2.5}$ and type 2 diabetes by distinct community types is a computationally simple strategy to mitigate place-based confounding; however, many studies of $\mathrm{PM}_{2.5}$ and type 2 diabetes across diverse geographies did not consider community type as a potential confounder.

The goal of this study is to evaluate the extent to which different exposure assignment choices and $\mathrm{PM}_{2.5}$ data sources impact these associations and the extent to which community type modifies the associations between $\mathrm{PM}_{2.5}$ and type 2 diabetes. We hypothesize that $\mathrm{PM}_{2.5}$ exposure estimates for participants in the REasons for Geographic And Racial Differences in Stroke (REGARDS) cohort will differ by the data source used and by the duration of exposures assigned prior to type 2 diabetes onset, which would lead to differences in estimated odds of diabetes. Second, we hypothesize that a census tract-level measure of community type (e.g., higher density urban, lower density urban, suburban/small town, and rural) will modify associations between $\mathrm{PM}_{2.5}$ and diabetes.

\section{METHODS \\ Study population}

Our analysis included participants from the REGARDS cohort. REGARDS is an observational study of risk factors for stroke in Black and white adults aged 45 years or older across the contiguous United States (US), with oversampling in the Southeastern US. Detailed study methods are published elsewhere [30]. Briefly, participants were selected from commercially available lists of residents and were recruited through a combination of mail notification and phone contact. Computer assisted phone interviews (CATI) were used to collect verbal consent and baseline risk factors, including demographics, smoking history, and cardiovascular risk factors. An in-home visit was then completed to collect blood pressure, blood and urine samples, and a signed informed consent, among other data. Follow-up phone contacts occur every six months to ascertain stroke events. A second extended CATI and in-home visit occurred $\sim 10$ years after the baseline, with similar data collected. The study is monitored and approved by institutional review boards at all participating institutions.

Participants included in this analysis had geocoded residential address information, were free from diabetes at baseline assessment (occurring in 2003-2007) and had observed diabetes status at a second in-home visit with blood glucose measurement and medication verification (occurring in 2013-2016). Diabetes was defined as: a fasting glucose measure of at least $126 \mathrm{mg} / \mathrm{dL}$ or a non-fasting glucose of at least $200 \mathrm{mg} / \mathrm{dL}$, or the use of oral diabetes medications or insulin at the follow-up in-home exam.

\section{$\mathrm{PM}_{2.5}$ exposures}

We obtained estimates of $\mathrm{PM}_{2.5}$ from three different data sources. The first was the Centers for Disease Control and Prevention Wide-ranging ONline Data for Epidemiologic Research (CDC WONDER) data [31], for which daily estimates of $\mathrm{PM}_{2.5}$ for the years 2003-2008 were available for REGARDS participants [32, 33]. This estimation method relied on an algorithm that incorporated air monitoring data from the United States Environmental Protection Agency Air Quality System (US EPA AQS) and satellite data from the National Aeronautics and Space Administration MODerate-resolution Imaging Spectroradiometer (NASA MODIS) estimation of Aerosol Optical Depth (AOD) [32]. Estimates were obtained for a $10 \mathrm{~km} \times 10 \mathrm{~km}$ national grid, and participants were assigned the value for the grid containing their residential location [33]. We generated exposure estimates by calculating the mean of daily $\mathrm{PM}_{2.5}$ estimates, a common approach for estimating individual exposures [34], for 1-year prior to each participant's baseline assessment using R for Statistical Computing [35] and Stata v.13 [36]. A small number of participants $(n=6)$ had a baseline interview date in early January of 2003, thus precluding the computation of exposure estimates since CDC WONDER data were not available prior to 2003. We also did not have exposure data assigned for an additional 5 individuals with baseline interviews in 2007, so we imputed estimates for a total of $n=11(0.1 \%)$ individuals using mean imputation.

The second $\mathrm{PM}_{2.5}$ dataset we examined is publicly available from the CDC through the National Environmental Health Tracking Network [37] and uses the US EPA Downscaler model [38]. This model uses AQS monitor data as well as data from the Community Multiscale Air Quality (CMAQ) model to supplement in areas with sparse monitoring networks. Census tract-level estimates of $\mathrm{PM}_{2.5}$ are available daily for the years 2001-2014. We generated exposure estimates from the Downscaler model by calculating the annual mean daily $\mathrm{PM}_{2.5}$ estimates for the 1- and 2-years prior to the year of each participant's baseline assessment.

Lastly, we obtained another publicly available $\mathrm{PM}_{2.5}$ dataset, global annual grid estimates provided by van Donkelaar et al. [39]. This source incorporated data from NASA MODIS, Multi-angle Imaging SpectroRadiometer (MISR) and Sea-viewing Wide Field-of-view Sensor (SeaWiFS) AOD data using geographically weighted regression to generate annual average estimates for the years 2000-2017, gridded at 0.01 degrees $(\sim 1.1 \mathrm{~km})$. We downloaded annual raster datasets and calculated the average $\mathrm{PM}_{2.5}$ value within a 1-mile radius around each participant's address using ArcGIS [40]. We assigned exposure estimates of: 1-year prior to baseline and the average of the two annual estimates for the 2-years prior to baseline.

\section{Covariates and community type definitions}

Demographic characteristics and behaviors were assessed via the baseline CATI and included: age, gender (M/F), race (Black/white), smoking status (current, former, never), educational attainment (<high school, high school graduate, some college, $\geq$ college graduate), and annual household income $(<\$ 20,000, \$ 20,000-\$ 34,000, \$ 35,000-\$ 74,000, \geq \$ 75,000$, refused to answer). Region was defined consistently with previous studies of this population (Stroke belt [Alabama, Arkansas, Louisiana, Mississippi, and Tennessee], buckle [North Carolina, South Carolina, and Georgia], non-belt [all other states in contiguous US]), identifying areas of higher stroke incidence in the Southeastern US [41]. Daily ambient temperature was estimated for REGARDS participants using the average of daily hourly data from the North American Land Data Assimilation System (NLDAS)[33]; we calculated annual average temperature for the year prior to the baseline assessment by averaging the daily values for each respective year.

Due to the potential for place-based confounding at the community level, we assigned each participant a community type (higher density urban, lower density urban, suburban/small town, and rural) for the census tract in which they resided. These classifications were derived from the US Department of Agriculture (USDA) Rural-Urban Commuting Area (RUCA) codes [42] and were modified to reflect the land area of each census tract based on the proportion of land area contained within a census-designated urbanized area or urban cluster, and by the size of tract land area [27].

\section{Statistical methods}

We first computed descriptive statistics for all individual-level and community variables assigned to participants using Stata 13.1 [36] and stratified these by diabetes status and, separately, by community type. We compared distributions of these variables by diabetes status using analysis of variance (ANOVA) for continuous variables and Pearson's $X^{2}$ tests for categorical variables. We calculated the mean $\mathrm{PM}_{2.5}$ exposures for each $\mathrm{PM}_{2.5}$ data source and duration, stratified by diabetes status, and we visualized the distributions of 1 -year $\mathrm{PM}_{2.5}$ estimates for each of the three $\mathrm{PM}_{2.5}$ sources with histograms stratified by community type.

To evaluate our primary associations of $\mathrm{PM}_{2.5}$ estimates with the odds of new onset diabetes at follow-up, we used generalized estimating equations with a binomial distribution, a logit link function, an exchangeable correlation structure to account for clustering of individuals in census tracts, and robust standard errors. Models were stratified by community type and adjusted for the following covariates: age (centered and centered-squared), race, gender, annual income, region, smoking status, and annual average temperature in the year prior to baseline. We scaled estimates of each $\mathrm{PM}_{2.5}$ exposure to estimate the odds of new onset diabetes per $5 \mu \mathrm{g} / \mathrm{m}^{3}$ increase in $\mathrm{PM}_{2.5}$ exposure for ease of interpretation and relevance to the levels observed in this sample.

We conducted several sensitivity analyses to assess the robustness of our primary associations, including additional adjustment for year of enrollment and educational status, separately. We also evaluated models of CDC WONDER estimates that excluded the 11 individuals for whom we imputed $\mathrm{PM}_{2.5}$ estimates. To assess associations of shorter durations of $\mathrm{PM}_{2.5}$ exposures with new onset diabetes, we conducted sensitivity analyses using exposure durations of 2 weeks and 30 days prior to baseline assessment using the two data sources with daily estimates available (CDC Wonder and CDC Downscaler). To assess associations of longer durations of $\mathrm{PM}_{2.5}$ exposures with new onset diabetes, we conducted sensitivity analyses using the CDC Downscaler data for participants with a baseline 
enrollment date in 2004, 2005, 2006, or 2007 for exposure durations of 3 years $(n=9277)$ and for participants with an enrollment date in 2005 , 2006 , or 2007 for exposure durations of 4 years $(n=5961)$. We were unable to evaluate longer exposure durations in the full sample because CDC Downscaler data were not available prior to 2001; however, we did assess correlation between exposure durations of $1,2,3$ and 4 years for participants with all exposure durations calculated $(n=5961)$.

\section{RESULTS}

Among the 11,208 participants free of diabetes at baseline, 1409 (12.6\%) had type 2 diabetes at follow-up (Table 1). Compared to those without diabetes $(n=9799)$, individuals with diabetes were slightly younger (62.2 [SD: 7.8] vs. 63.2 [SD: 8.6]); individuals with diabetes were more often: Black individuals (46.3\% vs. $30.8 \%)$, persons with annual income of $<\$ 20,000(16.9 \%$ vs. $10.5 \%)$, and persons who currently smoke $(15.4 \%$ vs. $10.5 \%)$. We did not observe any differences between community type and frequency of new onset diabetes ( $p=0.7$, Table 1). However, we did observe differences in some participant characteristics by community type (Table 2), including race, gender, educational attainment, annual income, smoking status, year of enrollment, region, and annual average temperature ( $p<0.001$ for each of these) and age ( $p=$ 0.009). These differences supported our a priori decision to stratify analyses of $\mathrm{PM}_{2.5}$ and new onset diabetes by community type.

Within community type, the distributions of 1-year $\mathrm{PM}_{2.5}$ estimates were similar across sources, except for rural areas, where estimates from the CDC WONDER model were slightly higher than for the other two $\mathrm{PM}_{2.5}$ sources (Fig. 1). Mean 1-year $\mathrm{PM}_{2.5}$ estimates from all three sources differed by community type $(p<0.001)$, with highest mean values in higher density urban community types and lowest mean values in rural community types (Fig. 1). We also evaluated the differences in $\mathrm{PM}_{2.5}$ estimates by diabetes status for all sources and durations (Table 3), and we observed significantly higher mean long-term $\mathrm{PM}_{2.5}$ estimates (1- and 2-year) for participants who had diabetes compared to those who did not, although the magnitude of these differences was small.

After adjusting for a priori defined covariates, we did not observe associations between any measure of $\mathrm{PM}_{2.5}$ exposure and incident diabetes within higher and lower density urban community types (Fig. 2). Within suburban/small town community types, odds of diabetes were higher per $5 \mu \mathrm{g} / \mathrm{m}^{3}$ increase in 1-year estimates of $\mathrm{PM}_{2.5}$ for each of the three sources evaluated (Fig. 2): CDC WONDER (OR [95\% Cl] per $5 \mu \mathrm{g} / \mathrm{m}^{3}$ increase in $\mathrm{PM}_{2.5}: 1.16[1.01,1.33]$ ), Downscaler (OR $[95 \% \mathrm{Cl}]$ per $5 \mu \mathrm{g} / \mathrm{m}^{3}$ increase in $\mathrm{PM}_{2.5}: 1.78[1.17$, $2.69])$, annual grid (OR $[95 \% \mathrm{Cl}]$ per $5 \mu \mathrm{g} / \mathrm{m}^{3}$ increase in $\mathrm{PM}_{2.5}: 1.59$ $[1.06,2.39])$. We also observed significant associations with diabetes for the 2-year annual grid estimates in suburban/small towns: Downscaler (OR $\left[95 \% \mathrm{Cl}\right.$ ] per $5 \mu \mathrm{g} / \mathrm{m}^{3}$ increase in $\mathrm{PM}_{2.5}: 1.65$ [1.09, $2.51])$, and annual grid (OR $[95 \% \mathrm{Cl}]$ per $5 \mu \mathrm{g} / \mathrm{m}^{3}$ increase in $\mathrm{PM}_{2.5}$ : $1.62[1.07,2.48])$. Within rural community types, the Downscaler and annual grid sources demonstrated trends of higher odds of diabetes with increasing duration of $\mathrm{PM}_{2.5}$ exposure; only the 2-year estimates of $\mathrm{PM}_{25}$ obtained from the Downscaler model were significantly associated with higher odds of diabetes: (OR [95\% CI]) per $5 \mu \mathrm{g} / \mathrm{m}^{3}$ increase in $\mathrm{PM}_{2.5}: 1.56$ [1.03, 2.36], Fig. 2).

Sensitivity analyses for models with the additional adjustment for participants' educational attainment or year of enrollment in REGARDS did not substantially or inferentially change our primary results, nor did the results of a model that excluded 11 individuals with imputed CDC WONDER estimates (results not shown). We did not observe any associations of $\mathrm{PM}_{2.5}$ with new onset type 2 diabetes when using shorter exposure durations of 2 weeks and 30 days prior to baseline enrollment for the CDC WONDER or Downscaler models (Supplementary Table S1). Among participants enrolled in 2005, 2006 and $2007(n=5961)$ for whom we were able to assign $\mathrm{PM}_{2.5}$ exposures of up to 4 years prior to baseline enrollment using the Downscaler model, Spearman
Table 1. Baseline participant characteristics by diabetes status at follow-up.

\begin{tabular}{|c|c|c|c|}
\hline \multirow[b]{2}{*}{ Variable } & \multicolumn{2}{|l|}{ Diabetes status } & \multirow[t]{2}{*}{$p$ value $^{a}$} \\
\hline & No $(n=9799)$ & $\begin{array}{l}\text { Yes } \\
(n=1409)\end{array}$ & \\
\hline Age (mean, SD) & $63.2(8.6)$ & $62.2(7.8)$ & $<0.001$ \\
\hline \multicolumn{4}{|l|}{ Race $(n, \%)$} \\
\hline White & $6777(69.2)$ & 757 (53.7) & \multirow[t]{2}{*}{$<0.001$} \\
\hline Black & $3022(30.8)$ & $652(46.3)$ & \\
\hline \multicolumn{4}{|l|}{ Gender $(n, \%)$} \\
\hline Male & $4297(43.9)$ & $655(46.5)$ & \multirow[t]{2}{*}{0.06} \\
\hline Female & $5502(56.1)$ & $754(53.5)$ & \\
\hline \multicolumn{4}{|l|}{ Education ( $n, \%)$} \\
\hline$<$ High school & $603(6.2)$ & $163(11.6)$ & \multirow[t]{4}{*}{$<0.001$} \\
\hline High school graduate & $2169(22.1)$ & $278(26.8)$ & \\
\hline Some college & $2521(25.7)$ & $400(28.4)$ & \\
\hline$\geq$ College graduate & $4505(46.0)$ & $468(33.2)$ & \\
\hline \multicolumn{4}{|l|}{ Income $(n, \%)$} \\
\hline$<\$ 20,000$ & $1032(10.5)$ & $238(16.9)$ & \multirow[t]{5}{*}{$<0.001$} \\
\hline$\$ 20,000-\$ 34,000$ & 2044 (20.9) & $339(24.1)$ & \\
\hline$\$ 35,000-\$ 74,000$ & $3342(34.1)$ & $474(33.6)$ & \\
\hline$\geq \$ 75,000$ & $2316(23.6)$ & $224(15.9)$ & \\
\hline Refused & 1065 (10.9) & $134(9.5)$ & \\
\hline \multicolumn{4}{|l|}{ Smoking status ( $n, \%)$} \\
\hline Current & $1029(10.5)$ & $216(15.4)$ & \multirow[t]{3}{*}{$<0.001$} \\
\hline Past & 3846 (39.4) & $568(40.5)$ & \\
\hline Never & $4893(50.1)$ & $619(44.1)$ & \\
\hline \multicolumn{4}{|l|}{ Community type $(n, \%)$} \\
\hline Higher density urban & $1584(16.2)$ & $223(15.8)$ & \multirow[t]{4}{*}{0.7} \\
\hline Lower density urban & $3940(40.2)$ & $587(41.2)$ & \\
\hline Suburban/small town & 1945 (19.9) & $279(19.8)$ & \\
\hline Rural & $2330(23.8)$ & $320(22.7)$ & \\
\hline \multicolumn{4}{|l|}{ Year of enrollment $(n, \%)$} \\
\hline 2003 & $1642(16.7)$ & $286(20.3)$ & \multirow[t]{5}{*}{0.002} \\
\hline 2004 & $2883(29.4)$ & 435 (30.9) & \\
\hline 2005 & $2139(21.8)$ & $272(19.3)$ & \\
\hline 2006 & $1690(17.3)$ & $214(15.2)$ & \\
\hline 2007 & $1445(14.8)$ & $202(14.3)$ & \\
\hline \multicolumn{4}{|c|}{ Region (US Census) ( $n, \%)$} \\
\hline Northeast & $713(7.3)$ & $84(6.0)$ & \multirow[t]{4}{*}{0.001} \\
\hline Midwest & $1526(15.4)$ & $213(15.1)$ & \\
\hline South & $6407(65.4)$ & $988(70.1)$ & \\
\hline West & $1153(11.8)$ & $124(8.8)$ & \\
\hline \multicolumn{4}{|l|}{ Region (REGARDS) $(n, \%)$} \\
\hline Belt & $713(7.3)$ & $84(6.0)$ & \multirow[t]{3}{*}{0.06} \\
\hline Buckle & $1526(15.4)$ & $213(15.1)$ & \\
\hline Nonbelt & $6407(65.4)$ & $988(70.1)$ & \\
\hline $\begin{array}{l}\text { Annual average } \\
\text { temperature, }{ }^{\circ} \mathrm{F} \text {, } \\
\text { mean (SD) }\end{array}$ & $61.8(6.7)$ & $61.5(6.5)$ & $<0.001$ \\
\hline
\end{tabular}

correlation coefficients for longer exposure durations were $\geq 0.94$ (Supplementary Table S2). We report only the effect estimates obtained from the sensitivity analysis of exposure durations of 3 years ( $n=9277$, Supplementary Table S3), as models with the 
Table 2. Baseline participant characteristics by community type.

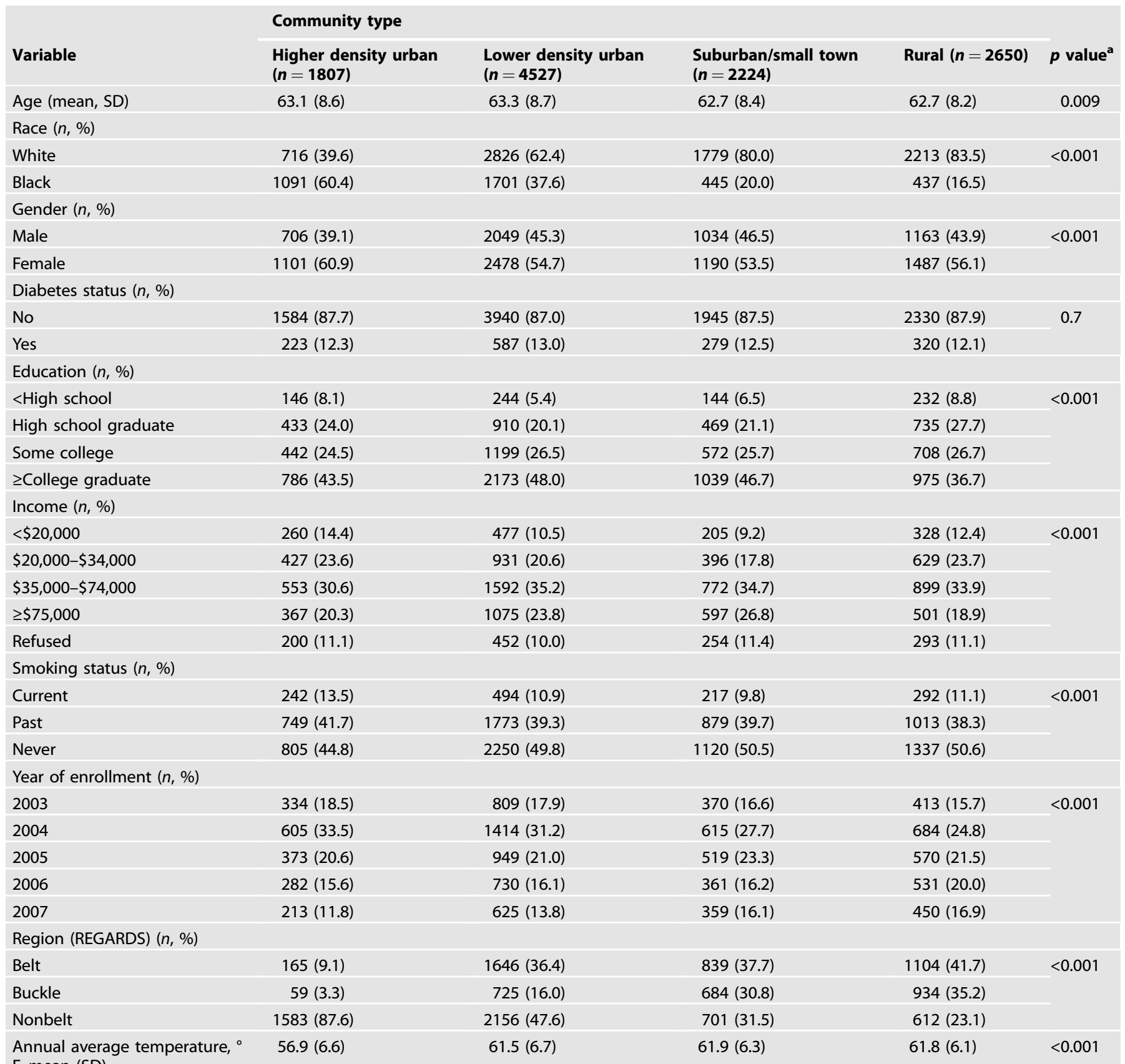

$\mathrm{F}$, mean (SD)

${ }^{a}$ For continuous variables, obtained from one-way ANOVA; for categorical variables, obtained from Pearson $\chi^{2}$.

4-year exposure estimates $(n=5961)$ were unable to achieve convergence due to reduced sample size. Among the 9277 participants for whom we were able to assign a 3-year exposure duration with the Downscaler model, the magnitude of effect estimates was similar to the primary models ( 1 \& 2 year durations); however, only the effect estimate within rural community types was statistically significant: (OR $[95 \% \mathrm{Cl}]$ per $5 \mu \mathrm{g} / \mathrm{m}^{3}$ increase in $\left.\mathrm{PM}_{2.5}: 1.66[1.03,2.65]\right)$.

\section{DISCUSSION}

Exposure estimates of $\mathrm{PM}_{2.5}$ were associated with higher odds of new onset type 2 diabetes in this study of 11,208 participants from the REGARDS cohort residing in suburban/small town and rural community types; however, these associations were only observed for exposure durations of at least 1-year. Observed associations were similar regardless of the data source of the $\mathrm{PM}_{2.5}$ exposure estimates. We did not observe associations between $\mathrm{PM}_{2.5}$ exposure estimates in higher density or lower density urban community types. These findings suggest that differences in the association of $\mathrm{PM}_{2.5}$ and type 2 diabetes by community type might account for some of the heterogeneity in the strength and significance of associations between $\mathrm{PM}_{2.5}$ and diabetes outcomes reported in the epidemiologic literature to date [28].

We found that longer term (1-year and 2-year) durations of $\mathrm{PM}_{2.5}$ exposures were associated with type 2 diabetes. These are 

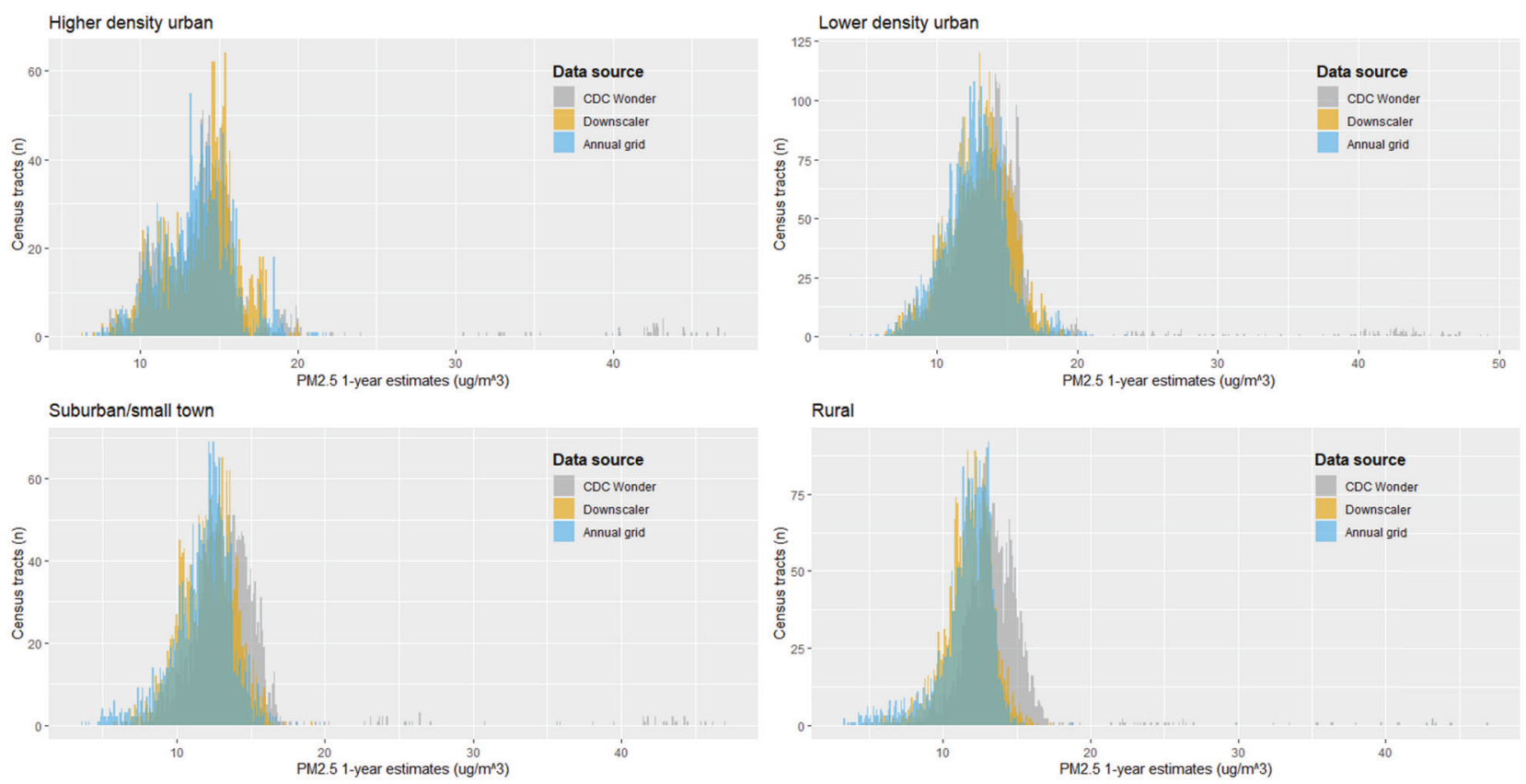

Fig. 1 Histograms of annual $\mathbf{P M}_{2.5}$ exposure estimates for three sources, stratified by community type. Each panel illustrates the community type-specific distributions of 1-year estimates for the CDC WONDER data source, the Downscaler data source, and the Annual grid data source.

Table 3. $\mathrm{PM}_{2.5}$ and constituent exposure, by source, duration, and diabetes status at follow-up.

\section{Diabetes status}

\begin{tabular}{|c|c|c|c|}
\hline Variable & No $(n=9799)$ & Yes $(n=1409)$ & $p$ value $^{a}$ \\
\hline \multicolumn{4}{|c|}{ CDC WONDER PM $2.5\left(\mu \mathrm{g} / \mathrm{m}^{3}\right.$, mean, SD) } \\
\hline 1-year duration & $13.8(4.1)$ & $14.1(4.2)$ & 0.03 \\
\hline \multicolumn{4}{|c|}{ Downscaler $\mathrm{PM}_{2.5}\left(\mu \mathrm{g} / \mathrm{m}^{3}\right.$, mean, SD) } \\
\hline 1-year duration & $12.7(2.1)$ & $12.8(2.1)$ & 0.01 \\
\hline 2-year duration & $12.8(2.2)$ & $12.9(2.1)$ & 0.03 \\
\hline \multicolumn{4}{|c|}{ Annual grid $\mathrm{PM}_{2.5}\left(\mu \mathrm{g} / \mathrm{m}^{3}\right.$, mean, $\left.\mathrm{SD}\right)$} \\
\hline 1-year duration & $12.4(2.2)$ & $12.6(2.1)$ & 0.001 \\
\hline 2-year duration & $12.4(2.2)$ & $12.6(2.1)$ & 0.001 \\
\hline
\end{tabular}

${ }^{a}$ Obtained from one-way ANOVA.

biologically plausible associations; development of type 2 diabetes is consistent with pathophysiologic mechanisms of systemic inflammation, dysfunction of insulin-producing $\beta$-cells, and glucose sensitivity associated with chronic $\mathrm{PM}_{2.5}$ exposures [28], so it is plausible that these associations were not present for the shorterterm exposure durations evaluated. It is also possible that the variation in shorter-term exposures may not capture the cumulative effects associated with a longer-term exposure. The magnitude of effect estimates observed for $5 \mu \mathrm{g} / \mathrm{m}^{3}$ increases in 1-year $\mathrm{PM}_{2.5}$ durations was also consistent with the sizes of effect estimates in other studies, though effect estimates within suburban/small towns from the Downscaler model and annual grid were approximately twice as large as the effect estimates commonly observed in the epidemiologic literature $[17,43,44]$. It is possible that effect estimates were stronger because of our community type stratification approach. While other studies $[17,45,46]$ of air pollution and incident diabetes have conducted analyses stratified by important factors (e.g., individual-level risk factors, region, year, neighborhoodlevel socioeconomic status), we have not identified any studies that evaluated $\mathrm{PM}_{2.5}$ and incident diabetes in the US in a community type stratified approach.
We did not observe any associations between $\mathrm{PM}_{2.5}$ estimates and new onset diabetes within higher density and lower density urban community types; however, we did observe differences in mean $\mathrm{PM}_{2.5}$ estimates by community types in the direction that we expected, with higher and lower density urban community types having higher mean $\mathrm{PM}_{2.5}$ compared to suburban/small towns and rural areas. In addition to potential exposure misclassification that is differential with respect to community type, it is possible that within community types, there is placebased confounding by community-level factors that are related to community type as well as diabetes onset, such as neighborhood walkability, healthy food access, and opportunities for recreational physical activity [24-26] that may impact potential associations and are contextually relevant to an individual's diabetes risk in urban vs. rural environments [47]. Future studies would need to carefully measure and evaluate these multidimensional and often overlapping community level factors that influence diabetes risk in addition to $\mathrm{PM}_{2.5}$ exposures.

We initially hypothesized that exposure estimates would differ depending on the method of exposure assessment used, and we expected the largest differences to be between exposure estimates from the annual grid, which were centered at the participants' homes and estimates from the CDC WONDER and Downscaler models, which were estimated for participants' census tracts. However, the distributions of these estimates and their values were relatively similar across sources and within community types, with an exception in rural community types, where estimates of $\mathrm{PM}_{2.5}$ from the CDC WONDER model were slightly larger than those from the Downscaler or annual grid models. The general concordance of estimates across methods gives us confidence in the accuracy of each exposure assessment method used and suggests that differing $\mathrm{PM}_{2.5}$ estimation methods are likely not the primary driver of mixed results in epidemiologic studies of $\mathrm{PM}_{2.5}$ and diabetes, although differing $\mathrm{PM}_{2.5}$ data sources not evaluated in this study could lead to conflicting results.

Our study is not without limitations. Primarily, we note that the exposure durations evaluated might not have been long enough to reflect chronic $\mathrm{PM}_{2.5}$ exposures relevant to diabetes risk. Mechanistically, it is very likely that new onset diabetes is a function of $\mathrm{PM}_{2.5}$ exposure of durations longer than 1 or 2 years. 

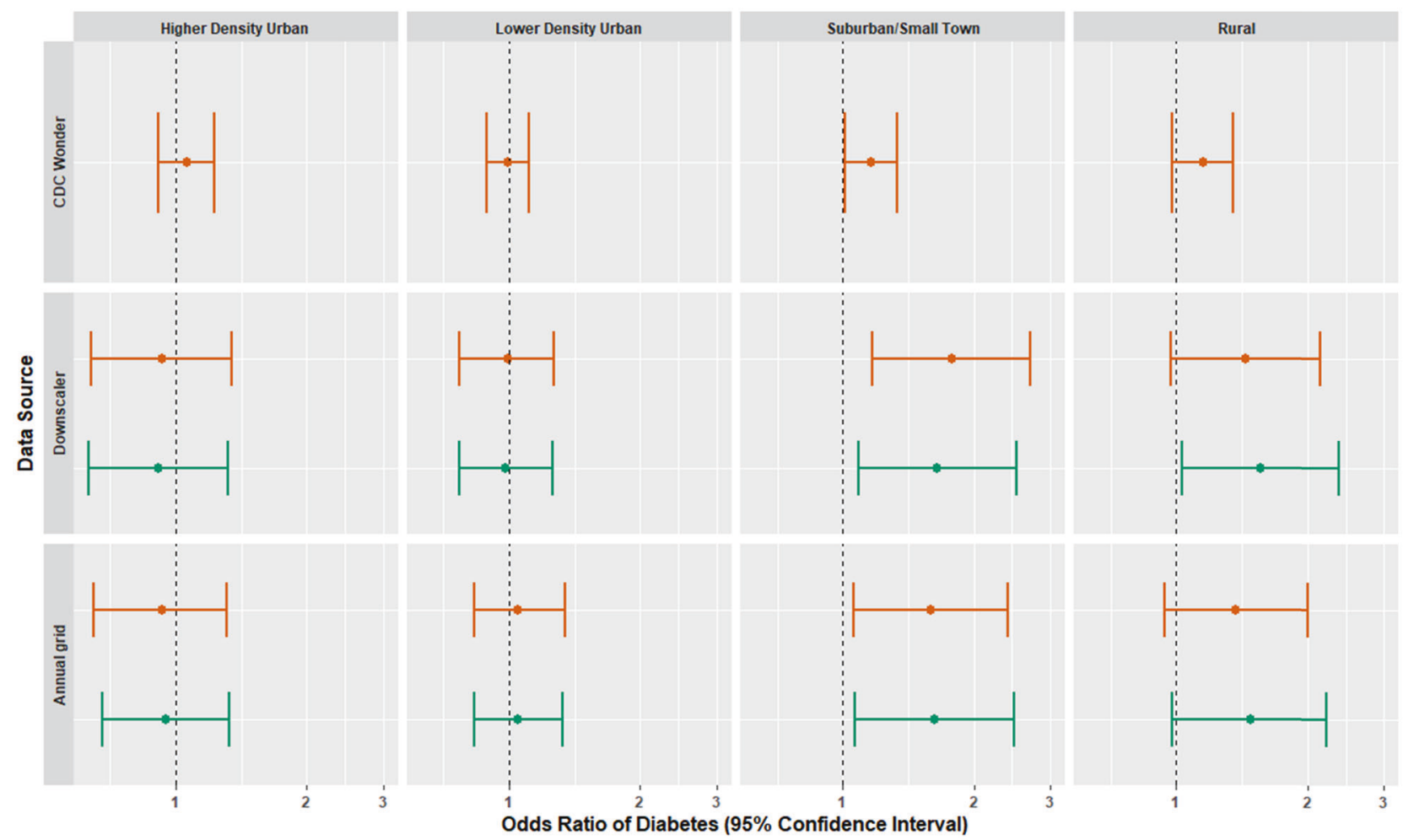

Odds Ratio of Diabetes (95\% Confidence Interval)

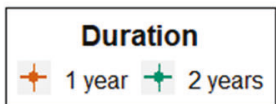

Fig. 2 Forest plots of estimated odd ratios and $95 \%$ confidence interval of new onset diabetes per 5 ug $/ \mathrm{m}^{3}$ increase of $P M_{2.5}, b$ community

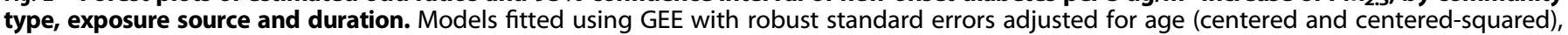
race, gender, income category, smoking status, annual average temperature, and region of REGARDS study, clustered on Census tract.

However, the availability and accuracy of historical $\mathrm{PM}_{2.5}$ data is a challenge [48], as are the limitations to historical residence information among participants in cohort studies [49]. Given these challenges, we believe the evaluation of durations of 1-year can be used to approximate long term exposure to $\mathrm{PM}_{2.5}$, and we observed high correlation among 1, 2, 3, and 4 year exposure estimates for a subset of individuals. We conclude that 1-year exposure durations are likely a sufficiently long enough exposure period for influencing diabetes risk in the years following, and that the 1-year measure likely serves as a good proxy for longer term exposure. Other limitations of this study include the potential for residual confounding by individual and community level factors not accounted for in our models. Further, we were unable to retrospectively understand participants' behavior with respect to daily indoor and outdoor activities that would influence their individual exposure to $\mathrm{PM}_{2.5}$. Presumably, having personal air pollution monitor information for these participants would give us a better understanding of each participants' actual $\mathrm{PM}_{2.5}$ exposure rather than what was assigned to their residential address.

There were also several strengths to this study. First, as our study sample was obtained from the REGARDS cohort, we had extensive survey and biometric health data from a large group of Black and white adults across the continental US. Although there have been other longitudinal studies of $\mathrm{PM}_{2.5}$ and type 2 diabetes, many studies have not been able to definitively exclude prevalent diabetes at baseline and therefore could not distinguish new onset diabetes from prevalent diabetes at follow-up; we were able to do so [28]. Another strength of this study is the examination of three differing exposure data sources to evaluate $\mathrm{PM}_{2.5}$, as each data source relied on slightly different methods (measurement and/or models) to estimate $\mathrm{PM}_{2.5}$ levels. However, estimates of
$\mathrm{PM}_{2.5}$ and their associations with new onset type 2 diabetes were comparable across all three data sources evaluated.

This study adds support to the epidemiologic evidence that longer-term $\mathrm{PM}_{2.5}$ exposures are associated with diabetes risk. Our results also demonstrate that consideration of community type is important, although we suspect that place-based confounding was still present in our observed associations, particularly within the urban community types. We know that community factors such as healthy food availability and walkability are related to both place and to diabetes risk; we suspect that the epidemiologic relationships among these variables are also complex. As the epidemiology of $\mathrm{PM}_{2.5}$ exposures expands to implicate more adverse health conditions, studies that evaluate $\mathrm{PM}_{2.5}$ exposure should also consider the role of multiple, overlapping neighborhood level exposures that impact diabetes risk. Accounting for these exposures in epidemiologic studies necessitates careful evaluation of place-based clustering within the exposure data, and, if present, the implementation of sophisticated statistical methods to account for highly correlated exposure variables and better understand diabetes risk.

\section{REFERENCES}

1. Yang $Y$, Ruan Z, Wang $X$, Yang $Y$, Mason TG, Lin H, et al. Short-term and long-term exposures to fine particulate matter constituents and health: a systematic review and meta-analysis. Environ Pollut. 2019;247:874-82.

2. Feng S, Gao D, Liao F, Zhou F, Wang X. The health effects of ambient PM2.5 and potential mechanisms. Ecotoxicol Environ Saf. 2016;128:67-74.

3. Donath MY, Shoelson SE. Type 2 diabetes as an inflammatory disease. Nat Rev Immunol. 2011;11:98-107.

4. Hotamisligil GS. Inflammation and metabolic disorders. Nature 2006;444:860-7.

5. Hummasti S, Hotamisligil GS. Endoplasmic reticulum stress and inflammation in obesity and diabetes. Circulation Res. 2010;107:579-91. 
6. Duncan BB, Schmidt MI, Pankow JS, Ballantyne CM, Couper D, Vigo A, et al. Lowgrade systemic inflammation and the development of type 2 diabetes: the atherosclerosis risk in communities study. Diabetes. 2003;52:1799-805.

7. Hu FB, Meigs JB, Li TY, Rifai N, Manson JE. Inflammatory markers and risk of developing type 2 diabetes in women. Diabetes. 2004;53:693-700.

8. Lin H, Guo Y, Zheng Y, Di Q, Liu T, Xiao J, et al. Long-term effects of ambient PM2.5on hypertension and blood pressure and attributable risk among older Chinese adults. Hypertension. 2017;69:806-12.

9. Kim M-J, Lim N-K, Choi S-J, Park H-Y. Hypertension is an independent risk factor for type 2 diabetes: the Korean genome and epidemiology study. Hypertension Res. 2015;38:783-9.

10. Hansen AB, Ravnskjær L, Loft S, Andersen KK, Bräuner EV, Baastrup R, et al. Longterm exposure to fine particulate matter and incidence of diabetes in the Danish Nurse Cohort. Environ Int. 2016;91:243-50.

11. Li C-Y, Wu C-D, Pan W-C, Chen Y-C, Su H-J. Association between long-term exposure to PM2.5 and incidence of type 2 diabetes in Taiwan. Epidemiology. 2019;30:S67-S75

12. Liang F, Yang X, Liu F, Li J, Xiao Q, Chen J, et al. Long-term exposure to ambient fine particulate matter and incidence of diabetes in China: a cohort study. Environ Int. 2019;126:568-75.

13. Park SK, Adar SD, O'Neill MS, Auchincloss AH, Szpiro A, Bertoni AG, et al. Longterm exposure to air pollution and type 2 diabetes mellitus in a multiethnic cohort. Am J Epidemiol. 2015;181:327-36.

14. Puett RC, Hart JE, Schwartz J, Hu FB, Liese AD, Laden F. Are particulate matter exposures associated with risk of type 2 diabetes? Environ Health Perspect. 2011;119:384-9.

15. Weinmayr G, Hennig F, Fuks K, Nonnemacher M, Jakobs H, Möhlenkamp S, et al. Long-term exposure to fine particulate matter and incidence of type 2 diabetes mellitus in a cohort study: effects of total and traffic-specific air pollution. Environmental Health. 2015;14:53.

16. Coogan PF, White LF, Yu J, Burnett RT, Seto E, Brook RD, et al. PM2.5 and diabetes and hypertension incidence in the Black Women's health study. Epidemiology. 2016;27:202-10.

17. Chen H, Burnett RT, Kwong JC, Villeneuve PJ, Goldberg MS, Brook RD, et al. Risk of incident diabetes in relation to long-term exposure to fine particulate matter in Ontario, Canada. Environ Health Perspect. 2013;121:804-10.

18. Krämer U, Herder C, Sugiri D, Strassburger K, Schikowski T, Ranft U, et al. Trafficrelated air pollution and incident type 2 diabetes: results from the SALIA cohort study. Environ Health Perspect. 2010;118:1273-9.

19. Clark C, Sbihi H, Tamburic L, Brauer M, Frank LD, Davies HW. Association of longterm exposure to transportation noise and traffic-related air pollution with the incidence of diabetes: a prospective cohort study. Environ Health Perspect. 2017;125:087025.

20. Eze IC, Foraster $M$, Schaffner $E$, Vienneau $D$, Héritier $H$, Rudzik $F$, et al. Long-term exposure to transportation noise and air pollution in relation to incident diabetes in the SAPALDIA study. Int J Epidemiol. 2017:46:1115-25.

21. Coogan PF, White LF, Jerrett M, Brook RD, Su JG, Seto E, et al. Air pollution and incidence of hypertension and diabetes mellitus in black women living in Los Angeles. Circulation 2012;125:767-72.

22. Balti EV, Echouffo-Tcheugui JB, Yako YY, Kengne AP. Air pollution and risk of type 2 diabetes mellitus: a systematic review and meta-analysis. Diabetes Res Clin Pr. 2014;106:161-72.

23. Auchincloss AH, Roux AVD, Mujahid MS, Shen M, Bertoni AG, Carnethon MR Neighborhood resources for physical activity and healthy foods and incidence of type 2 diabetes mellitus: the multi-ethnic study of atherosclerosis. Arch Intern Med. 2009;169:1698-704.

24. Christine PJ, Auchincloss AH, Bertoni AG, Carnethon MR, Sánchez BN, Moore K et al. Longitudinal associations between neighborhood physical and social environments and incident type 2 diabetes mellitus: the multi-ethnic study of atherosclerosis (MESA). JAMA Intern Med. 2015;175:1311-20.

25. Kolak M, Bhatt J, Park YH, Padrón NA, Molefe A. Quantification of neighborhoodlevel social determinants of health in the continental United States. JAMA Netw Open. 2020;3:e1919928

26. Humphrey J, Lindstrom M, Barton K, Shrestha P, Carlton E, Adgate J, et al. Social and environmental neighborhood typologies and lung function in a low-income, Urban Population. Int J Environ Res Public Health. 2019;16:1133.

27. McAlexander TP, Algur Y, Schwartz BS, Rummo PE, Lee D, Siegel KR, et al. Categorizing community type for epidemiologic evaluation of community factors and chronic disease across the United States. Under Review at Social Sci Humanities Open. 2021.

28. Alderete TL, Chen Z, Toledo-Corral CM, Contreras ZA, Kim JS, Habre R, et al Ambient and traffic-related air pollution exposures as novel risk factors for metabolic dysfunction and type 2 diabetes. Curr Epidemiol Rep. 2018; 5:79-91.
29. Di Q, Kloog I, Koutrakis P, Lyapustin A, Wang Y, Schwartz J. Assessing PM2.5 exposures with high spatiotemporal resolution across the continental United States. Environ Sci Technol. 2016;50:4712-21.

30. Howard VJ, Cushman M, Pulley L, Gomez CR, Go RC, Prineas RJ, et al. The reasons for geographic and racial differences in stroke study: objectives and design. Neuroepidemiology 2005;25:135-43.

31. CDC. 2019. http://wonder.cdc.gov.

32. Al-Hamdan MZ, Crosson WL, Limaye AS, Rickman DL, Quattrochi DA, Estes MG, et al. Methods for characterizing fine particulate matter using ground observations and remotely sensed data: potential use for environmental public health surveillance. J Air Waste Manag Assoc. 2009;59:865-81.

33. McClure LA, Loop MS, Crosson W, Kleindorfer D, Kissela B, Al-Hamdan M. Fine particulate matter $(\mathrm{PM}(2.5))$ and the risk of stroke in the REGARDS cohort. J Stroke Cerebrovasc Dis. 2017;26:1739-44.

34. Diao M, Holloway T, Choi S, O'Neill SM, Al-Hamdan MZ, Van Donkelaar A, et al. Methods, availability, and applications of PM2.5 exposure estimates derived from ground measurements, satellite, and atmospheric models. J Air Waste Manag Assoc. 2019;69:1391-414.

35. Team; RC. R: a language and envrionment for statistical computing. Vienna, Austria: R Foundation for Statistical Computing; 2012.

36. StataCorp. Stata statistical software: release 13. College Station, TX: StataCorp LP; 2013.

37. CDC. National environmental health tracking network. https://ephtracking.cdc. gov/showHome.

38. Vaidyanathan A, Dimmick Wf, Kegler SR, Qualters JR. Statistical air quality predictions for public health surveillance: evaluation and generation of county level metrics of PM2.5 for the environmental public health tracking network. Int J Health Geogr. 2013;12.

39. van Donkelaar A, Martin RV, Brauer M, Hsu NC, Kahn RA, Levy RC, et al. Global estimates of fine particulate matter using a combined geophysical-statistical method with information from satellites, models, and monitors. Environ Sci Technol. 2016;50:3762-72.

40. ESRI. ArcGIS Pro 2.4.2. Redlands, CA: Environmental Systems Research Instittue; 2019.

41. Shrira I, Christenfeld N, Howard G. Exposure to the US Stroke Buckle as a risk factor for cerebrovascular mortality. Neuroepidemiology. 2008;30:229-33.

42. Economic Research Service, USDA. 2010 Rural-Urban Commuting Area (RUCA) Codes: United States Department of Agriculture; 2019. https://www.ers.usda.gov/ data-products/rural-urban-commuting-area-codes/documentation/.

43. Bowe B, Xie Y, Li T, Yan Y, Xian H, Al-Aly Z. The 2016 global and national burden of diabetes mellitus attributable to PM 2.5 air pollution. Lancet Planet Health. 2018;2:e301-e12.

44. Thiering E, Markevych I, Brüske I, Fuertes E, Kratzsch J, Sugiri D, et al. Associations of residential long-term air pollution exposures and satellite-derived greenness with insulin resistance in German adolescents. Environ Health Perspect. 2016;124:1291-8.

45. Eze IC, Imboden M, Kumar A, Von Eckardstein A, Stolz D, Gerbase MW. et al. Air pollution and diabetes association: Modification by type 2 diabetes genetic risk score. Environ Int. 2016;94:263-71.

46. Hernandez AM, Gimeno Ruiz De Porras D, Marko D, Whitworth KW. The association between PM2.5 and ozone and the prevalence of diabetes mellitus in the United States, 2002 to 2008. J Occup Environ Med 2018;60:594-602.

47. Kegler MC, Alcantara I, Haardörfer R, Gemma A, Ballard D, Gazmararian J. Rural neighborhood walkability: implications for assessment. J Phys Act Health 2015;12:S40-S5. s1.

48. Kim S-Y, Olives C, Sheppard L, Sampson PD, Larson TV, Keller JP. et al. Historical prediction modeling approach for estimating long-term concentrations of PM2.5 in cohort studies before the 1999 implementation of widespread monitoring. Environ Health Perspect. 2017;125:38-46.

49. Pereira G, Bracken MB, Bell ML. Particulate air pollution, fetal growth and gestational length: the influence of residential mobility in pregnancy. Environ Res. 2016;147:269-74.

\section{ACKNOWLEDGEMENTS}

The authors would like to acknowledge support from the Diabetes LEAD (Location, Environmental Attributes, and Disparities) Network, a research collaboration among the Centers for Disease Control and Prevention (CDC) and Drexel University (coordinating center), Geisinger - Johns Hopkins University, New York University School of Medicine, and University of Alabama at Birmingham. We also thank the other investigators, the staff, and the participants of the Reasons for Geographic and Racial Differences in Stroke study for their valuable contributions. A full list of participating Reasons for Geographic and Racial Differences in Stroke investigators and institutions can be found at http:// www.regardsstudy.org. 


\section{AUTHOR CONTRIBUTIONS}

TM: Conceptualization, data analysis, manuscript development; SD: Data analysis, manuscript review; MM: Data analysis, manuscript review; LL: Statistical review, manuscript review; LM: Conceptualization, statistical review, manuscript review

\section{FUNDING INFORMATION}

This project was conducted with funding support from the Centers for Disease Control and Prevention (CDC U01DP006293). The REGARDS study is supported and cofunded by the National Institute of Neurological Disorders and Stroke and the National Institute on Aging (cooperative agreement U01 NS041588). The content is solely the responsibility of the authors and does not necessarily represent the official views of the National Institute of Neurological Disorders and Stroke or the National Institute on Aging. Representatives of the National Institute of Neurological Disorders and Stroke were involved in the review of the manuscript but not directly involved in the collection, management, analysis, or interpretation of the data.

\section{COMPETING INTERESTS}

The authors declare no competing interests.

\section{ADDITIONAL INFORMATION}

Supplementary information The online version contains supplementary material available at https://doi.org/10.1038/s41370-021-00391-9.
Correspondence and requests for materials should be addressed to Tara P. McAlexander.

Reprints and permission information is available at http://www.nature.com/ reprints

Publisher's note Springer Nature remains neutral with regard to jurisdictional claims in published maps and institutional affiliations. C. Attribution 4.0 International License, which permits use, sharing, adaptation, distribution and reproduction in any medium or format, as long as you give appropriate credit to the original author(s) and the source, provide a link to the Creative Commons license, and indicate if changes were made. The images or other third party material in this article are included in the article's Creative Commons license, unless indicated otherwise in a credit line to the material. If material is not included in the article's Creative Commons license and your intended use is not permitted by statutory regulation or exceeds the permitted use, you will need to obtain permission directly from the copyright holder. To view a copy of this license, visit http://creativecommons. org/licenses/by/4.0/.

(c) The Author(s) 2021 